\title{
Intestinal ion transport and the pathophysiology of diarrhea
}

\author{
Michael Field \\ Department of Medicine, and Department of Physiology and Cellular Biophysics, College of Physicians and Surgeons, Columbia University, \\ New York, New York, USA
}

J. Clin. Invest. 111:931-943 (2003). doi:10.1172/JCI200318326.

Worldwide, diarrhea claims several million lives annually, mostly those of infants. Poverty, crowding, and contaminated water supplies all contribute. Almost all of these deaths could have been prevented with adequate fluid replacement. Although its incidence is much lower in the more affluent nations, diarrhea remains one of the two most common reasons for visits to pediatric emergency departments and is also common among the institutionalized elderly. Chronic diarrheas, while less common, often present diagnostic dilemmas and can be difficult to manage. This article will begin by reviewing the relevant physiology; then, with that as context, it will consider pathophysiology, both general aspects and specific diarrheal syndromes. Finally, rationales for management will be briefly considered. The review is amply referenced with some of the references listed at the end of the article and some at the JCI website (http://www.jci.org/cgi/content/full/111/7/931/DC1).

\section{Physiology}

All segments of intestine from duodenum to distal colon have mechanisms for both absorbing and secreting water and electrolytes. This review begins with a historical approach to the development of knowledge in the field, considering absorption and secretion separately, although, inevitably, the processes involved are interconnected.

\section{Absorption}

Over the last half-century, two key sets of observations have energized and organized research in this area. The first was the discovery in the 1960s that sugars (glu-

The Science in Medicine series is supported in part by a generous grant from the Doris Duke Charitable Foundation.

Address correspondence to: Address correspondence to: Michael Field, 299 Riverside Drive, Apartment 9D, New York, New York 10025, USA.E-mail:mf9@columbia.edu.

Conflict of interest: The author has declared that no conflict of interest exists.

Nonstandard abbreviations used: $\mathrm{Na} / \mathrm{H}$ exchanger (NHE); downregulated in adenoma (DRA); putative anion transporter 1 (PAT1); cholera toxin (CT); protein kinase A (PKA); cystic fibrosis (CF); cystic fibrosis transmembrane conductance regulator (CFTR); NHE3 kinase A regulatory protein (E3KARP); vasoactive intestinal peptide (VIP); enteric nervous system (ENS); heat-stable toxin (STa); cGMP-dependent protein kinase (PKG); oral rehydration solution (ORS). cose and galactose) and amino acids are absorbed across the small-intestinal brush border membrane via carriers that couple their movements to that of $\mathrm{Na}^{+}(1)$. $\mathrm{Na}^{+}$coupling permits the organic solute to be transported uphill, i.e., from low luminal to higher cell concentration, a gradient opposite to that for $\mathrm{Na}^{+}$. The organic solutes then move downhill from enterocyte to blood via basolateral membrane carriers that operate independently of ion movements. As discovered subsequently, some oligopeptides, instead of being first hydrolyzed into amino acids, are absorbed intact across the intestinal brush border by a proton-coupled mechanism. This absorptive process is indirectly coupled to $\mathrm{Na}^{+}$transport, since the needed protons are provided by $\mathrm{Na} / \mathrm{H}$ exchange, which acidifies the unstirred layer abutting the brush border membrane $(2, \mathrm{~S} 1)$. The $\mathrm{Na}^{+}$gradient, therefore, is the driving force for amino acid, oligopeptide, and sugar absorption. As these organic solutes are absorbed, salt is absorbed with them, and water follows osmotically - transport from enterocyte to lateral intercellular space creates a local osmotic gradient that initiates water flow. As described below, the coupled transport of $\mathrm{Na}^{+}$and organic solute is the theoretical basis for oral rehydration therapy in severe diarrhea.

The second key set of observations arose from studies, performed in the late 1960s on human subjects, of intestinal salt absorption in the absence of nutrients $(3,4)$. Segments of jejunum and ileum were perfused with solutions of varied electrolyte composition, and the appearance or disappearance of ions and water was recorded. The data suggested different transport mechanisms in jejunum and ileum. In the jejunum, $\mathrm{NaHCO}_{3}$ is absorbed via $\mathrm{Na} / \mathrm{H}$ exchange (the secreted $\mathrm{H}^{+}$neutralizes an equivalent amount of luminal $\mathrm{HCO}_{3}^{-}$) and $\mathrm{Cl}^{-}$movement is purely passive. In the ileum (and, as shown later, also in the proximal colon) ( $\mathrm{S} 2), \mathrm{NaCl}$ is absorbed via equal rates of $\mathrm{Na} / \mathrm{H}$ and $\mathrm{Cl} / \mathrm{HCO}_{3}$ exchanges.

Three $\mathrm{Na} / \mathrm{H}$ exchangers (NHEs) have since been localized to intestinal brush border membranes and cloned; NHE2 and NHE3 are found in both small intestine and colon $(5, \mathrm{~S} 3)$. NHE3 appears to be quantitatively more important, since the NHE2 knockout mouse suffers gastric dysfunction but no intestinal disability (S4) whereas the NHE3 knockout mouse suffers from 


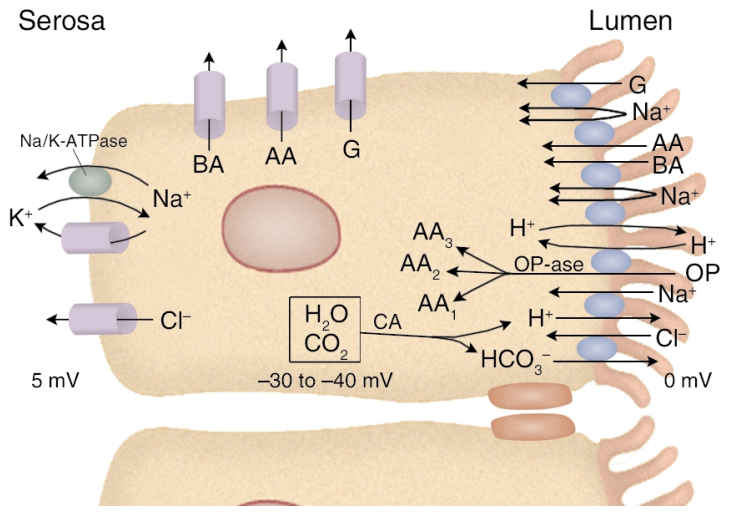

Figure 1

Ileal absorptive cell. Multiple brush border transporters couple ion influxes $\left(\mathrm{Na}^{+}\right.$and, in one instance, $\left.\mathrm{H}^{+}\right)$to organic solute influxes or exchange one ion for another. Basolateral-membrane carriers facilitate diffusion of organic solutes and are not coupled to ion movements. $\mathrm{Na} / \mathrm{K}-\mathrm{ATP}$ ase in the basolateral membrane uses energy from ATP hydrolysis to drive $\mathrm{Na}^{+}$extrusion and $\mathrm{K}^{+}$uptake ( $3: 2$ stoichiometry), both moving against their electrochemical gradients. $\mathrm{K}^{+}$and $\mathrm{Cl}^{-}$channels in the basolateral membrane open in response to cell swelling and elevations of intracellular $\mathrm{Ca}^{2+}$. Some of the cellular $\mathrm{H}^{+}$and $\mathrm{HCO}_{3}-$ extruded in exchange for $\mathrm{Na}^{+}$and $\mathrm{Cl}^{-}$is provided through the action of carbonic anhydrase (CA). Additional $\mathrm{HCO}_{3}{ }^{-}$may enter the cell through the basolateral membrane $\mathrm{NHE} 1$ or the $\mathrm{Na}\left(\mathrm{HCO}_{3}\right)_{3}$ cotransporter (not shown). The cell electric potential is $30-40 \mathrm{mV}$ negative relative to the lumen, providing an electric, as well as a chemical, driving force for $\mathrm{Na}^{+}$ entry via $\mathrm{Na}$-organic solute cotransport. $\mathrm{G}$, glucose or galactose; $\mathrm{AA}$, amino acid (there are actually several amino acid carriers); BA, bile acid anion; OP, oligopeptide; OPase, oligopeptidase (almost all oligopeptides entering the cell intact are quickly hydrolyzed).

chronic diarrhea (6). A third, Cl-dependent NHE is found in crypt cells of rat distal colon (S5). The NHE first identified in intestine, NHE1, is present only in the basolateral membrane of enterocytes and is involved in $\mathrm{HCO}_{3}{ }^{-}$secretion (see below).

Two anion exchangers have also been localized to small-intestinal and colonic brush border membranes and cloned (7, S6). They have been given curious names: downregulated in adenoma (DRA) and putative anion transporter 1 (PAT1). DRA was first cloned from colonic mucosa; it was found to be downregulated in villus adenomas and carcinomas (S7)and subsequently was found to incur mutations in the rare diarrheal disorder familial chloride diarrhea (8) (see "Congenital diarrheas" below). Both DRA and PAT1 are abundant in the duodenum and present at higher density there than NHE2 and NHE3, suggesting a role in duodenal alkalinization (S8). In the colon, DRA appears to predominate over PAT1 (S6).

More than two brush border ion exchangers are required, of course, for the enterocyte to engage in transcellular salt absorption. Increased turnover of the $\mathrm{Na} / \mathrm{K}$ pump and the opening of $\mathrm{Cl}^{-}$and $\mathrm{K}^{+}$channels are also necessary, the latter to counteract associated cell swelling, to permit serosal exit of $\mathrm{Cl}^{-}$taken up from the lumen, and to dissipate the added uptake of $\mathrm{K}^{+}$ through the pump. The cellular mechanisms involved are summarized in Figure 1.

\section{Secretion}

Knowledge about secretion arose from two sources: university research laboratories preoccupied with intestinal physiology, or with epithelial physiology more generally, and field stations in Asia dedicated to cholera research. As investigators moved back and forth between field stations and universities, these initially separate groups came together. Until the late 1960s, despite emerging research into cholera (see below), the gut was generally thought of as an absorptive epithelium. Rare reports of active secretion by intestinal epithelium were largely ignored (S9). In 1965, an Annual Review of Physiology article entitled "Secretory mechanisms of the digestive tract" did not even mention intestinal secretion (S10), whereas, in 1970, the same annual published a review devoted to intestinal secretion (S11).

Critical to cholera research were two essentially simultaneous reports in 1959, one from Calcutta (9), the other from Bombay (10), that a cell-free filtrate of a Vibrio cholerae culture will elicit fluid secretion when instilled into the intestines of rabbits, proving that a substance released by the bacteria (cholera toxin) is responsible. A year later, in a report on small-bowel biopsies taken from both acutely ill and convalescent cholera patients, the intestinal epithelium was demonstrated to remain intact, seemingly uninjured by the cholera organism and its toxins (11). These two reports set the stage for the investigation of cholera as an active-transport disease, or, more specifically, for exploration of the possibility that cholera toxin (CT) behaves like a luminally active hormone, stimulating the intestinal epithelium to actively secrete electrolytes and water. However, because cholera researchers, like other gastrointestinal tract physiologists, were not yet prepared to think of the intestine as a secretory epithelium, alternative explanations were initially proposed that ultimately proved wrong.

In the late 1960s and into the 1970s, the ion transport properties of rabbit ileum were systematically examined in vitro using the isolated mucosa (stripped of muscle) mounted in so-called Ussing chambers. cAMP and agents that increase its intracellular concentration were shown to have two striking and mutually reinforcing effects on ion transport: (a) stimulation of active $\mathrm{Cl}^{-}$secretion "active" refers here to uphill transport, i.e., transport against an electrochemical gradient), and (b) inhibition of active, electroneutral $\mathrm{NaCl}$ absorption $(12, \mathrm{~S} 12)$. Coupled absorption of $\mathrm{Na}^{+}$and glucose was not affected. The implication of these observations for the pathophysiology of diarrhea was obvious, and these investigators quickly began a collaboration with cholera researchers to explore the possible role of cAMP in cholera in particular and diarrheal disease more generally. The collaboration soon established that CT, when added to rabbit ileal mucosa in Ussing chambers, produces the same effects as cAMP, albeit with a slower time course, and does so by stimulating adenylyl cyclase activity in enterocytes $(13,14)$.

Over the next decade, the individual cell membrane transporters contributing to active $\mathrm{Cl}^{-}$secretion were 
functionally identified, giving rise to a model of general applicability to several electrolyte-secreting organs (Figure 2). cAMP, via protein kinase A (PKA), stimulates secretion by activating or enhancing the transport activities of three membrane proteins:

1. The apical anion channel. cAMP opens the apical anion channel (to be precise, it increases the probability of its opening), thereby initiating secretion (15). In the intestine, at least, cAMP also promotes insertion of additional channels (recruited from the ER) into the apical membrane (S13, S14).

2. A basolateral membrane $K^{+}$channel. The opening of a basolateral membrane $\mathrm{K}^{+}$channel repolarizes the cell, counteracting the depolarizing effect of opening the $\mathrm{Cl}^{-}$channel and thus sustaining the electrical driving force for $\mathrm{Cl}^{-}$extrusion into the lumen. A cAMP-activatable $\mathrm{K}^{+}$channel has recently been identified and cloned (16, S15, S16).

3. A basolateral membrane $\mathrm{NaK2Cl}$ cotransporter. The turnover of a basolateral membrane $\mathrm{NaK} 2 \mathrm{Cl}$ cotransporter $(17, \mathrm{~S} 17)$ determines the maximal rate of serosal $\mathrm{Cl}^{-}$entry (once the apical anion channel and the basolateral membrane $\mathrm{K}^{+}$channel have been activated). cAMP appears to enhance cotransporter activity not via PKA-induced phosphorylation of the transport protein, but indirectly by opening the apical anion channel and thereby decreasing cell $\left[\mathrm{Cl}^{-}\right]$, and also by enhancing cotransporter insertion into the basolateral membrane from an intracellular storage site (S17, S18).

The inherited disease cystic fibrosis (CF) develops when dysfunctional mutations occur in the gene for the cAMP-responsive apical anion channel. Accordingly, this channel, which is present in a number of tissues, has been dubbed the cystic fibrosis transmembrane conductance regulator or CFTR for short. CFTR is a member of the superfamily of $\mathrm{ABC}$ proteins and has a single-channel conductance of 7-10 pS and a linear current-voltage relationship (18). Studies of intestine from both humans and transgenic mice with CF show a near total absence of electrolyte secretion $(19,20)$, which perhaps explains why patients with CF occasionally develop intestinal obstruction (known, in neonates, as meconium ileus).

Not only is cAMP's secretory effect lost in CF, but its inhibition of electroneutral $\mathrm{NaCl}$ absorption is also lost, indicating a critical role for normal CFTR in the latter. The mechanism for cAMP's (and also $\mathrm{Ca}^{2+}$ s) inhibition of electroneutral $\mathrm{NaCl}$ absorption is not fully elucidated but is known to involve several proteins, including NHE3 kinase A regulatory protein (E3KARP), NHE regulatory factor (NHERF), ezrin, and $\alpha$-actinin-4 (S19-S21). NHE3, DRA, and CFTR all possess affinity for a discrete binding domain on E3KARP. It has recently been proposed that CFTR, NHE3, and either DRA or PAT1 bind to one domain of E3KARP (which dimerizes in the process) (S19, S20) and that signal transduction proteins such as PKA (via ezrin) (S21) bind to a second domain. Whether PKA inhibits electroneutral $\mathrm{NaCl}$ absorption by activating the bound CFTR or through a more direct effect on E3KARP remains to be determined.

\section{Regulation of absorption and secretion}

Once a role for cAMP in gut electrolyte secretion was established, the hunt was on for regulatory endocrine/paracrine/neural compounds. Two classes of compounds emerged: those that stimulate active secretion and inhibit active absorption, and those with the opposite effects (Table 1). The former group includes four kinds of agents: (a) neurotransmitters, including vasoactive intestinal peptide (VIP), acetylcholine, substance $P$, and the nucleotides ATP and UTP; (b) the paracrine agents serotonin and neurotensin, which are released by endocrine (enterochromaffin) cells in the intestinal epithelium; (c) agents released by inflammatory cells, including mainly prostaglandins and leukotrienes but also platelet-activating factor (which causes other inflammatory cells to release prostaglandins) (S22), histamine, and serotonin; and (d) guanylin, a luminally active peptide released into the gut lumen by goblet cells (see "Toxigenic E. coli" below).

Among these compounds, cAMP mediates the action of VIP, UTP/UDP, and prostaglandins (at high concentration). The action of guanylin is mediated by cGMP (see below). For all of the others (including lower concentrations of prostaglandins), activation of their receptors increases intracellular $\mathrm{Ca}^{2+}$ and activates PKC. The $\mathrm{Ca}^{2+}$ increase opens a basolateral $\mathrm{K}^{+}$channel dif-

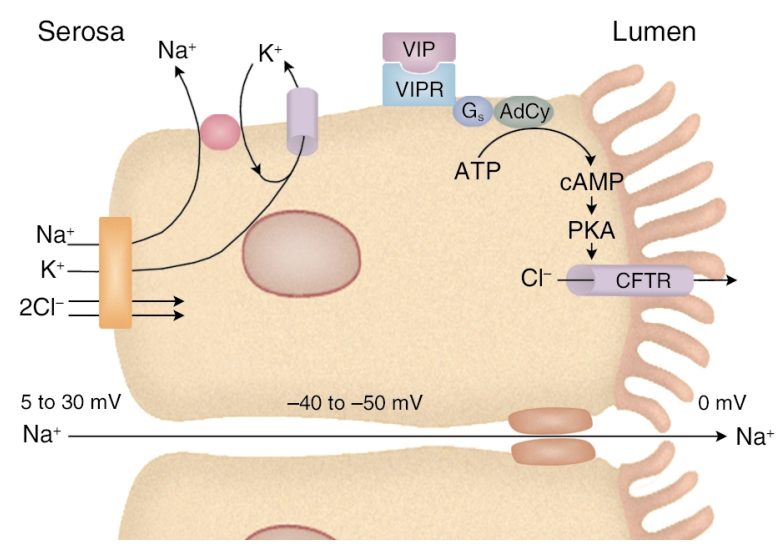

\section{Figure 2}

Intestinal $\mathrm{Cl}^{-}$secretion. CFTR, the apical anion channel, mutations in which cause cystic fibrosis, is opened by PKA-catalyzed phosphorylations (its activity can also be enhanced through protein kinase G- and PKCinduced phosphorylations). The VIPR receptor is a $\mathrm{G}$ protein-linked activator of adenylyl cyclase (AdCy). The electroneutral $\mathrm{NaK} 2 \mathrm{Cl}$ cotransporter facilitates the coupled movement of these ions across the basolateral membrane. The drop in cell $\left[\mathrm{Cl}^{-}\right]$that follows opening of the apical anion channel enables an inward flux of the three ions. Cotransporter activity also increases in response to cell shrinkage. When CFTR is opened, the resulting anion efflux depolarizes the cell's electric potential. The repolarization required to maintain secretion is accomplished through the opening of a cAMP-sensitive, $\mathrm{Ca}^{2+}$-insensitive $\mathrm{K}^{+}$channel in the basolateral membrane. During secretion, the cell electric potential is 40-50 $\mathrm{mV}$ negative and the serosal potential is $5-30 \mathrm{mV}$ positive, both relative to the lumen (the serosal potential tends to be closer to $5 \mathrm{mV}$ in the small intestine and $30 \mathrm{mV}$ in the distal colon). The transmural potential difference drives $\mathrm{Na}^{+}$movement into the lumen through the tight junctions via the lateral intercellular spaces. 
Table 1

Local control of intestinal ion transport

\begin{tabular}{|c|c|c|c|c|}
\hline Agonist & Source & Target cell(s) & Intracellular mediator(s) & $\begin{array}{l}\text { Secondary mediator(s) of } \\
\text { transporting epithelial cell effects }\end{array}$ \\
\hline \multicolumn{5}{|c|}{ Secretory/Antiabsorptive stimuli } \\
\hline VIP (S91) & Neural & Epith & cAMP & \\
\hline $\operatorname{ACh}(S 92,593)$ & Neural & Epith, neural, mes & $\mathrm{Ca}^{2+}, \mathrm{PKC}$ & Eicos, ? VIP \\
\hline SP (S94-S96) & Neural & Neural, mast, epith & $\mathrm{Ca}^{2+}, \mathrm{PKC}$ & Histamine, eicos \\
\hline ATP/ADP (S97) & Neural & Mes, epith & $\mathrm{Ca}^{2+}, \mathrm{PKC}$ & Eicos \\
\hline UTP/UDP (S97) & Neural & Mes, epith & cAMP & Eicos \\
\hline 5-HT (S98, S99) & EC, mast cell & Neural, epith & $\mathrm{Ca}^{2+}, \mathrm{PKC}$ & VIP and ACh \\
\hline NT (S94, S100) & $\mathrm{EC}$ & Neural & $\mathrm{Ca}^{2+}, \mathrm{PKC}$ & Eicos, adeno, VIP, and ACh \\
\hline Guanylin (39) & Goblet cells & Epith & cGMP & \\
\hline PGs $(13$, S101) & Mes & Epith, neural & $\mathrm{Ca}^{2+}, \mathrm{PKC} ; \mathrm{cAMP}$ & \\
\hline LTs, pre-LTs (S28, S102) & Mes & Epith, neural & $\mathrm{Ca}^{2+}, \mathrm{PKC}$ & \\
\hline $\operatorname{PAF}(\mathrm{S} 22, \mathrm{~S} 103)$ & Mes & Mes & $\mathrm{Ca}^{2+}, \mathrm{PKC} ; \mathrm{cAMP}$ & Eicos \\
\hline Histamine (S104, S105) & Mast cell & Mes, neural & $\mathrm{Ca}^{2+}, \mathrm{PKC} ; \mathrm{cAMP}$ & Eicos, VIP, ACh \\
\hline Bradykinin (S106) & Vascular & Mes & $\mathrm{Ca}^{2+}, \mathrm{PKC} ; \mathrm{cAMP}$ & Eicos \\
\hline Adenosine (S107-S111) & Epith, lumen & Epith, mes & $\begin{array}{l}\text { A1 R: } \mathrm{Ca}^{2+}, \mathrm{PKC} \\
\text { A2 R: cAMP }\end{array}$ & PGs (not LTs) \\
\hline Endothelin-1 (S112) & Vascular & Mes & $\mathrm{Ca}^{2+}, \mathrm{PKC} ; \mathrm{cAMP}$ & PGs \\
\hline \multicolumn{5}{|c|}{ Antisecretory/Proabsorptive stimuli } \\
\hline Norepi $(22$, S32, S113) & Neural & Epith, neural & Activate $G_{i}$ & \\
\hline NPY (S32, S114-S117) & Neural, EC & Epith, neural & $?$ & ? Norepi \\
\hline SST (S26, S118, S119) & EC, neural & Epith, neural & Activate $\mathrm{G}_{\mathrm{i}}(\mathrm{SST}$ R2) & \\
\hline Enkeph (S120, S121) & Neural & Epith, neural & $?$ & \\
\hline 12-HETE (S27) & Mes & Epith & Block BL K+ channel & \\
\hline
\end{tabular}

Epith, epithelial; ACh, acetylcholine; mes, mesenchymal cell (fibroblast, neutrophil, eosinophil, lymphocyte, mast cell, etc.); SP, substance P; eicos, eicosanoids (prostaglandins, leukotrienes, and their precursors); 5-HT, 5-hydroxy-tryptamine (serotonin); EC, enterochromaffin or epithelial endocrine cell; NT, neurotensin; adeno, adenosine; PG, prostaglandin; LT, leukotriene; PAF, platelet-activating factor; R, receptor; norepi, norepinephrine; $\mathrm{G}_{i}$, inhibitory G protein; NPY, neuropeptide Y; SST, somatostatin; enkeph, enkephalins (opioids); 12-HETE, 12-hydroxyeicosatetraenoic acid; BL, basolateral. Numbers in parentheses indicate references.

ferent from that opened by cAMP (21). Based on studies with other tissues, PKC activation may either directly open the CFTR anion channel or heighten its sensitivity to PKA (S23-S25).

A striking difference between the effects of cyclic nucleotide-dependent secretagogues and Ca-dependent ones is evident in vitro. The former cause persistent secretion, whereas the latter cause transient secretion and the swift development of tachyphylaxis. This difference may be less pronounced in vivo, since the relevant effectors are quickly removed by hydrolysis and blood flow, perhaps thereby preventing or reversing tachyphylaxis.

The group of compounds that both inhibit active secretion $\left(\mathrm{HCO}_{3}{ }^{-}\right.$as well as $\left.\mathrm{Cl}^{-}\right)$and enhance active absorption includes norepinephrine (via $\alpha_{2}$-receptors), neuropeptide $Y$, enkephalins, all neurotransmitters, and somatostatin, both a neurotransmitter and a paracrine agent (S26). Among leukotriene precursors, 12-hydroxyeicosatetraenoic acid is antisecretory, blocking the basolateral membrane $\mathrm{Ca}^{2+}$-activated $\mathrm{K}^{+}$channel (S27). Other leukotriene precursors are secretory stimuli (S28).

With a multitude of locally produced compounds providing bidirectional regulation of intestinal ion transport, it is not surprising that the system can be fine-tuned for a variety of circumstances. In the small intestine, so-called basal conditions may in fact represent a low rate of secretion (S29). Attempting to outline the complex, multifaceted relationships among epithelial ion-transporting cells, epithelial endocrine cells, mesenchymal cells (fibroblasts, mast cells, neutrophils, T and B lymphocytes, eosinophils, etc.), and nerves is beyond the scope of this review. Some of the complexity can be gleaned from Table 1. A few points can be emphasized as follows.

The enteric nervous system (ENS) consists of two plexi, the myenteric (between the circular and the longitudinal smooth muscle layers) and the submucosal, along with their interconnections. Both plexi contain so-called secreto-motor nerves that release agonists with either direct or indirect effects on epithelial ion transport. In the isolated (muscle-stripped) mucosal preparation, the submucosal plexus is usually retained, but not the myenteric. That the former alone profoundly influences ion transport is evident from the effect of adding tetrodotoxin to this preparation (S30).

VIP and acetylcholine are the predominant transmitters with direct epithelial secretory and/or antiabsorptive effects released by secreto-motor nerves; acetylcholine also acts on other neurons and on mesenchymal cells.

The mast cell is a key mediator for epithelial-neural interactions in allergic reactions and some parasitic infections (S31). Activation of mucosal mast cells by IgE or a variety of agonists including substance $\mathrm{P}$, acetylcholine, and neurotensin causes release of histamine, serotonin, rat mast cell protease II (which appears to enhance absorption of macromolecules), prostaglandins, leukotrienes, and platelet-activating factor. 
Norepinephrine, the predominant antisecretory/proabsorptive agonist in the intestines, activates $\alpha_{2}$-receptors on both enterocytes (22) and nerves (S32, S33). The neural effect is inhibitory, blocking release of secretion-inducing neurotransmitters. The direct epithelial effect (and perhaps also the neural effect) is exerted, in part at least, through inhibition of adenylyl cyclase. Adrenergic fibers are present in the submucosal plexus.

\section{Other transport and permeability properties}

Barrier function. In addition to transporting ions, nutrients, and water, the intestinal epithelium, consisting of both enterocytes and their encircling tight junctions (zona occludens), functions as a barrier that restricts the flow of luminal contents into the blood and lymphatics and vice versa. In the small intestine, tight junctions are, on the average, of the low-resistance type, meaning that most of the passive permeability of the epithelium to small monovalent ions and water resides in these junctional complexes (tight junctions in villi have higher resistance than do those in crypts) (S34). Colonic intercellular junctions are tighter, their resistance increasing steadily from proximal to distal portions. Although these junctions, which comprise a number of discrete proteins, are extracellular, their permeability properties are regulated by intracellular structures, especially actin filaments (23).

Osmolarity of intestinal contents. Unlike renal tubules, the intestines neither dilute nor concentrate their contents, the osmolarity of which, except in duodenum and proximal jejunum shortly after eating, is the same as plasma osmolarity (24). Although it may seem counterintuitive, the osmolarity of ions and molecules in stool water is also identical to plasma osmolarity (S35).

Other ion transport mechanisms and their geography. Mechanisms vary both longitudinally, along the length of the intestines, and horizontally, along the crypt-to-villus or crypt-to-surface cell axis.

Longitudinally, differences exist in $\mathrm{Na}^{+}$entry mechanisms, sites of $\mathrm{HCO}_{3}{ }^{-}$secretion, and sites of active $\mathrm{K}^{+}$ transport. $\mathrm{Na}^{+}$crosses small-intestinal and colonic brush borders via $\mathrm{Na} / \mathrm{H}$ exchange and, in the small bowel, also by $\mathrm{Na}$-organic solute cotransport. In the distal colon, luminal $\mathrm{Na}^{+}$is also absorbed via an aldosterone-sensitive $\mathrm{Na}^{+}$channel that belongs to the same molecular family as does the channel in the distal renal tubule (S36). In hyperaldosteronemic states (dehydration, liver disease, and heart failure), colonic $\mathrm{Na}^{+}$absorption (and therefore also $\mathrm{Cl}^{-}$and water absorption) is enhanced.

$\mathrm{HCO}_{3}{ }^{-}$is absorbed in the jejunum (via $\mathrm{Na} / \mathrm{H}$ exchange) and secreted in the duodenum, ileum, and colon. Its secretion can be explained in part by $\mathrm{Cl} / \mathrm{HCO}_{3}$ exchange (when it is not offset by $\mathrm{Na} / \mathrm{H}$ exchange), but most intestinal $\mathrm{HCO}_{3}^{-}$secretion appears to occur via CFTR, which is permeable to both $\mathrm{HCO}_{3}{ }^{-}$and $\mathrm{Cl}^{-}$; the relative rates of secretion of $\mathrm{HCO}_{3}{ }^{-}$ and $\mathrm{Cl}^{-}$appear to be determined by cell-to-lumen concentration differences and by their relative conductivity through CFTR (25). At the enterocyte's basolateral membrane, $\mathrm{HCO}_{3}$ - entry involves both $\mathrm{Na} / \mathrm{H}$ exchange and $\mathrm{Na}\left(\mathrm{HCO}_{3}\right)_{3}$ cotransport (S37-S39).
Active absorption and secretion of $\mathrm{K}^{+}$both occur in the colon, but neither occurs in the small intestine, where $\mathrm{K}^{+}$movement is strictly diffusional. $\mathrm{K}^{+}$is actively absorbed in distal colon via an $\mathrm{H} / \mathrm{K}$-ATPase homologous to the gastric $\mathrm{H} / \mathrm{K}$-ATPase responsible for acid secretion and is actively secreted throughout the colon via apical $\mathrm{K}^{+}$channels $(26, \mathrm{~S} 40, \mathrm{~S} 41) . \mathrm{K}^{+}$absorption is enhanced by $\mathrm{Na}^{+}$and $\mathrm{K}^{+}$depletion and inhibited by cAMP. $\mathrm{K}^{+}$secretion is enhanced by chronic dietary $\mathrm{K}^{+}$ loading and by cAMP.

Horizontally, the anatomic sites for secretion and absorption have traditionally been thought to differ, secretion occurring in crypts and absorption in smallintestinal villi and colonic surface cells. This undoubtedly overreaching generalization is consistent with some studies but not others. In support, (a) hypertonic disruption of small-intestinal villus cells does not reduce CT-induced secretion (27); (b) in distal colon, intracellular microelectrode recordings have shown appropriate electrical responses to secretory stimuli only in crypt cells, not in surface cells (S42, S43); and (c) almost all CFTR molecules have been localized to small-intestinal and colonic crypts by immunofluorescence and in situ hybridization $(28,29)$. Intriguingly, however, occasional villus cells, representing $3 \%$ of the total, immunostain positive for CFTR (30). These cells, which superficially resemble neighboring villus cells but lack brush border disaccharidases, may be secretory. Alternatively, they may represent a high-conductance route for passive $\mathrm{Cl}^{-}$movement.

On the other hand, microperfusion of individual crypts dissected from distal colon has demonstrated base-line absorption and agonist-inducible secretion (31). Does this dual functionality also apply to smallintestinal crypts? Probably not. Colonic crypts are much larger, their cells constituting most of the epithelium; in contrast, small-intestinal crypt cells normally constitute only about $20 \%$ of the epithelium. Furthermore, an apical NHE has not been found in small-intestinal crypt cells (32, S44); an apical anion exchanger is present (32), but it alone cannot enable fluid absorption.

Not all investigators will agree (S45, S46), but the following conclusions seem best supported by the evidence: (a) in small intestine, most, but conceivably not all, secretion arises from crypts, and all, or nearly all, absorption arises from villi; and (b) in colon, crypts display both absorption and secretion, but surface cells only absorb. In distal colon, $\mathrm{Na}^{+}$channel-mediated absorption is confined to surface cells (S47).

Due to this at-least partial separation of absorptive and secretory functions, the latter predominate in diseases that selectively damage villar or surface epithelium (e.g., enteric infection, inflammatory bowel disease, celiac sprue). This predominance is further accentuated in celiac disease, because crypt hypertrophy also develops.

Table 2, which lists the various cell membrane transport proteins that collectively account for the intestinal tract's absorptive and secretory processes for electrolytes, provides a somewhat cryptic summary of much of the above. One entry in the table is not referred to above: $\mathrm{ClC}-4$, a second apical $\mathrm{Cl}^{-}$channel in mouse and 
Table 2

Intestinal transport proteins

\begin{tabular}{|c|c|c|c|c|c|}
\hline \multirow{2}{*}{$\begin{array}{l}\text { Transport } \\
\text { process }\end{array}$} & \multirow{2}{*}{$\begin{array}{l}\text { lons } \\
\text { transported }\end{array}$} & \multirow[t]{2}{*}{ Species } & \multicolumn{2}{|c|}{ Location } & \multirow{2}{*}{$\begin{array}{l}\text { Associated gene defect } \\
(\mathrm{m} \text { or } \mathrm{h})\end{array}$} \\
\hline & & & $\mathrm{A} / \mathrm{BL}$ & Horizontal/vertical distribution & \\
\hline \multirow[t]{7}{*}{$\mathrm{NaCl}$ abs } & $\mathrm{Na} / \mathrm{H}$ & NHE2 $(5$, S3, S4) & A & $\mathrm{SI}, \mathrm{DC}(\mathrm{V}$ and $\mathrm{SC}>\mathrm{Cr})$ & Gastric atrophy $(\mathrm{m})$ \\
\hline & & $\operatorname{NHE3}(5,6, \mathrm{~S} 3, \mathrm{~S} 4)$ & A & $\mathrm{SI}, \mathrm{PC}(\mathrm{V}, \mathrm{SC}>>\mathrm{Cr})$ & Chronic diarrhea $(\mathrm{m})$ \\
\hline & & Cl-dep. NHE (S5) & A & $\mathrm{DC}(\mathrm{Cr})$ & \\
\hline & $\mathrm{Cl} / \mathrm{HCO}_{3}$ & $\operatorname{dra}(7,8, S 8)$ & A & Duod, ileum, $\mathrm{C}(\mathrm{V}$ and $\mathrm{Cr})$ & Familial $\mathrm{Cl}^{-}$diarrhea $(\mathrm{h})$ \\
\hline & & PAT1 (S6) & A & Duod, ileum $>C$ & \\
\hline & $\mathrm{K}^{+}$ & $\begin{array}{l}\text { High G; } \mathrm{Ca}^{2+} \text {, stretch-activated } \\
(21, \mathrm{~S} 122-\mathrm{S} 125)\end{array}$ & BL & Throughout & \\
\hline & $\mathrm{Cl}^{-}$ & CIC-2; PKC-activated (S126, S127) & $B L$ & Throughout & \\
\hline \multirow[t]{2}{*}{$\mathrm{Na}^{+}$abs } & $\mathrm{Na}^{+}$ & $\mathrm{ENa}(\sim 4 \mathrm{pS})(\mathrm{S} 36, \mathrm{~S} 47)$ & A & $\mathrm{DC}(\mathrm{SC})$ & \\
\hline & $\mathrm{K}^{+}$ & High G; $\mathrm{Ca}^{2+}$, stretch-activated & $\mathrm{BL}$ & & \\
\hline \multirow[t]{5}{*}{$\mathrm{Cl}^{-}$secr } & $\mathrm{Cl}^{-}$ & CFTR $(\sim 7 p S)(15, S 13, S 14)$ & A & Throughout (cr >> V, SC) & Cystic fibrosis $(\mathrm{m}, \mathrm{h})$ \\
\hline & & ClC-4 (S49) & A & Same as for CFTR & \\
\hline & $\mathrm{K}^{+}$ & $\begin{array}{l}\text { High G (200-300 pS); } \mathrm{Ca}^{2+} \text {, } \\
\text { stretch-activated }\end{array}$ & $\mathrm{BL}$ & Throughout & \\
\hline & & $\begin{array}{l}\text { Low G, cAMP-activated; } \\
(16, \mathrm{~S} 15, \mathrm{~S} 16, \mathrm{~S} 121, \mathrm{~S} 125, \mathrm{~S} 126)\end{array}$ & $\mathrm{BL}$ & Throughout $(\mathrm{cr}>>\mathrm{V})$ & \\
\hline & $\mathrm{Na}^{+}, \mathrm{K}^{+}, \mathrm{Cl}^{-}$ & NKCC1 $(17, \mathrm{~S} 17, \mathrm{~S} 18)$ & $\mathrm{BL}$ & Throughout & \\
\hline \multirow[t]{2}{*}{$\mathrm{HCO}_{3}{ }^{-}$abs } & $\mathrm{Na}^{+}, \mathrm{H}^{+}$ & NHE2, NHE3 & A & Jej $(V)$ & \\
\hline & $\mathrm{K}^{+}$ & $\begin{array}{l}\text { High G (200-300 pS); } \mathrm{Ca}^{2+} \text {, } \\
\text { stretch-activated }\end{array}$ & BL & & \\
\hline \multirow[t]{4}{*}{$\mathrm{HCO}_{3}{ }^{-} \mathrm{secr}$} & $\mathrm{Cl} / \mathrm{HCO}_{3}$ & Dra, PAT1 & A & Duod, ileum, C (V, SC, cr) & \\
\hline & $\mathrm{HCO}_{3}^{-}$ & CFTR (25) & A & Duod, ileum, C (cr >> V) & \\
\hline & $\mathrm{Na} / \mathrm{H}$ & NHE1 & $\mathrm{BL}$ & Throughout (cr, V, SC) & \\
\hline & $\mathrm{Na}\left(\mathrm{HCO}_{3}\right)_{3}$ & NBC1 $(\mathrm{S} 37, \mathrm{~S} 38)$ & $\mathrm{BL}$ & Duod, PC & \\
\hline \multirow[t]{2}{*}{$\mathrm{K}^{+} \mathrm{abs}$} & $\mathrm{K} / \mathrm{H}$ & $\mathrm{H}^{+} / \mathrm{K}^{+}$-ATPase (26) & A & DC & \\
\hline & $\mathrm{K}^{+}$ & High G; $\mathrm{Ca}^{2+}$, stretch-activated & $\mathrm{BL}$ & & \\
\hline \multirow[t]{3}{*}{$\mathrm{K}^{+}$secr } & $\mathrm{K}^{+}$ & High G, aldo-activated (S40, S41) & A & $C(\mathrm{cr})$ & \\
\hline & $\mathrm{Na}^{+}, \mathrm{K}^{+}, 2 \mathrm{Cl}^{-}$ & NKCC1 & $\mathrm{BL}$ & Throughout & \\
\hline & $\mathrm{Na} / \mathrm{K}$ & $\mathrm{Na} / \mathrm{K}$-ATPase & $\mathrm{BL}$ & Throughout & \\
\hline
\end{tabular}

Since the action of $\mathrm{Na} / \mathrm{K}-\mathrm{ATP}$ ase on the basolateral membrane is central to all of these ion transport processes, its involvement is assumed without mention, except in the instance of $\mathrm{K}^{+}$secretion, where it serves as a $\mathrm{K}^{+}$-loading mechanism. A, apical membrane; BL, basolateral membrane; $\mathrm{m}$, transgenic mouse; $\mathrm{h}$, human; abs, absorption; SI, small intestine; PC, proximal colon; V, villus; SC, colonic surface cell; Cr, crypt; dep., dependent; DC, descending colon; dra, downregulated in adenoma; duod, duodenum; C, colon; $\mathrm{G}$, conductance; $\mathrm{ENa}, \mathrm{NA}^{+}$channel; secr, secretion; aldo, aldosterone.

human intestine that belongs to the family of $\mathrm{ClC}$ anion channels (S48) and that colocalizes with CFTR (S49). It is activated by depolarization but the effects, if any, of intracellular mediators or extracellular regulators on its activity are unknown. Whether its variable expression can explain the far more severe intestinal disease that occurs in CF knockout mice than in humans with $\mathrm{CF}$ is unclear. $\mathrm{ClC}-4$ has been detected in both murine and human intestine. Only minimal secretion, which is not increased by traditional effectors, has been observed in CF intestinal preparations. Since CF gene mutations generally interfere with CFTR traffic to the apical membrane (S50), and since normal CFTR is a regulator of other membrane transporters and ion channels, apical placement of ClC-4 may also be affected in CF. It will be interesting to look at $\mathrm{ClC}-4$ expression in $\mathrm{CF}$ intestine.

\section{Pathophysiology: general aspects}

Patients may use the word diarrhea for increases in stool mass (in adults, up to $250 \mathrm{~g} / \mathrm{d}$ is considered normal), stool liquidity, or stool frequency. The first criterion truly defines diarrhea, but patients rarely provide quantitative information on their daily stool output. The other two criteria suggest the first, but occasionally stool frequency or liquidity increases without an appreciable increase in stool mass. Most such instances constitute a purely functional disorder known as irritable bowel syndrome, which is responsible for at least $25 \%$ of all visits to gastroenterologists. Although moderate increases in stool mass (500-1,000 g/d) need medical attention if they persist, this review is mainly concerned with more severe diarrheas - those that can lead to dehydration.

Two caveats about diarrhea are worth stressing. First, significant malabsorption of nutrients does not always cause diarrhea, since the normal adult colon's reabsorptive capacity is about $5 \mathrm{l} / \mathrm{d}$. Second, patients may develop profuse diarrhea in the absence of nutrient malabsorption or even histologically evident mucosal damage or inflammation, as, for example, when the small intestine's immense secretory capacity is triggered by a bacterial enterotoxin.

\section{Diarrheal driving forces}

Osmosis, active secretion, exudation, and altered motility can all drive diarrhea. Specific diarrheal illnesses often involve more than one of these forces. 
Osmotic diarrbea. When poorly absorbable, low-molecular weight aqueous solutes are ingested, their osmotic force quickly pulls water and, secondarily, ions into the intestinal lumen. Individuals with normal gut function will develop osmotic diarrhea when they ingest large amounts of poorly absorbable solutes, such as lactulose (if they are being treated for hepatic encephalopathy), sorbitol (if they continually chew sugar-free gum), or $\mathrm{Mg}^{2+}$ (if they take certain antacids or bowel purgatives).

Osmotic diarrhea can also develop when an ordinarily absorbable nutrient is ingested by an individual with an absorptive defect, for example, lactose by someone with congenital lactase deficiency, or carbohydrate by someone with gluten-sensitive enteropathy (celiac disease). Maldigestion, as seen in pancreatic insufficiency, may cause osmotic diarrhea of colonic origin: unabsorbed carbohydrates and lipids, on reaching the colon, are hydrolyzed by bacteria into short-chain organic acids, the quantity of which may overwhelm the colon's capacity for their absorption.

Secretory diarrhea. Diarrhea resulting from overstimulation of the intestinal tract's secretory capacity can develop in "pure" form (e.g., cholera) or as a component of a more complex disease process (e.g., celiac disease, Crohn disease). "Pure" secretory diarrhea is characterized by (a) large stool volumes (which can exceed 1 liter per hour in well hydrated adults), (b) absence of red or white blood cells in the stool, (c) absence of fever or other systemic symptoms (except those due to dehydration), (d) persistence of diarrhea with fasting (volume may diminish, however), and (e) lack of excess osmotic gap in stool electrolytes. Osmotic gap (OG) is defined as follows: $\mathrm{OG}=290-2\left\{\left[\mathrm{Na}^{+}\right]+\left[\mathrm{K}^{+}\right]\right\}$, where 290 is the assumed osmolarity of blood plasma. A gap greater than $50 \mathrm{mM}$ is considered abnormal (S51); the normal gap is made up of $\mathrm{Mg}^{2+}, \mathrm{Ca}^{2+}, \mathrm{NH}_{4}^{+}$, and perhaps organic cations. The pattern of stool electrolytes in patients with acute cholera shows $\mathrm{Na}^{+}, \mathrm{K}^{+}$, and $\mathrm{Cl}^{-}$ concentrations not very different from those in plasma and an $\mathrm{HCO}_{3}{ }^{-}$concentration somewhat higher then in plasma. In contrast, normal stool shows low $\left[\mathrm{Na}^{+}\right]$and high $\left[\mathrm{K}^{+}\right]$concentrations, due mainly to the colon's reabsorption of $\mathrm{Na}^{+}$and secretion (both active and passive) of $\mathrm{K}^{+}$; and a low $\left[\mathrm{Cl}^{-}\right]$concentration, due to the replacement of $\left[\mathrm{Cl}^{-}\right]$by short-chain organic acid anions generated by colonic bacteria. Normally, $\left[\mathrm{HCO}_{3}{ }^{-}\right]$concentration is similar to that in plasma.

A number of secretory stimuli can cause diarrhea. These include bacterial enterotoxins, hormones generated by endocrine neoplasms, dihydroxy bile acids, hydroxylated fatty acids, and inflammatory mediators. In the absence of vigorous fluid replacement, marked dehydration leading to vascular collapse can occur, as can severe losses of $\mathrm{K}^{+}$and $\mathrm{HCO}_{3}{ }^{-}$.

Exudative diarrhea. If the intestinal epithelium's barrier function is compromised by loss of epithelial cells or disruption of tight junctions, hydrostatic pressure in blood vessels and lymphatics will cause water and electrolytes, mucus, protein, and sometimes even red and white cells to accumulate luminally (e.g., ulcerative colitis, shigellosis, intestinal lymphangiectasia). If the con- dition is chronic, the continuing protein loss can lead to hypoalbuminemia and hypoglobulinemia.

Diarrhea resulting from motility disturbances. Both increases and decreases in gut motility can lead to diarrhea. Examples of the former are thyrotoxicosis and opiate withdrawal. Decreases in effective motility in the small intestine due to large diverticula, smooth muscle damage (scleroderma, dematomyositis, amyloidosis, muscular dystrophy, or radiation injury), or autonomic neuropathy (diabetic, idiopathic) can result in bacterial overgrowth. As specified below, bacterial overgrowth can lead to diarrhea.

\section{Pathophysiology of acute diarrheas}

\section{Enteric infection with enterotoxin-producing bacteria}

Summarized here is information on three bacterial enterotoxins produced by two enteric organisms, $V$. cholerae and Escherichia coli. In fact, similar toxic peptides are produced by Yersinia (S52) and Salmonella (S53) and perhaps other enteropathogenic bacteria.

$V$. cholerae. We are in the midst of a worldwide pandemic of cholera, due to biotype El Tor, that apparently began in the 1960s (S54). The disease is now or has been recently prevalent in India, Bangladesh, Pakistan, Indochina, Indonesia, Afghanistan, Africa, South America, and Mexico. Although it is rare in the US, 61 proven cases were reported to the Centers for Disease Control from 1995-2000 (S55). More than half were acquired during travel abroad, and most of the others were acquired from undercooked imported seafood. The organism appears to inhabit estuaries (in a form that is difficult to culture) and to spread to human populations under conditions of contaminated water supplies, inadequate sewage disposal, crowding, and malnutrition. Wars and earthquakes are inciting factors.

Every medical student now learns the mechanism of action of CT, the V. cholerae enterotoxin. CT is an $84-\mathrm{kDa}$ protein consisting of a dimeric $\mathrm{A}$ subunit and five identical B subunits (Figure 3). The A subunit consists of two peptides linked by an S-S bond, the larger, A1, containing the toxic activity. Each of the B subunits binds tightly to the GM1 ganglioside abundant in the intestinal brush border membrane (33); binding is so tight that only the normal 5- to 7-day turnover of the epithelium eliminates toxicity. The toxin's A1 subunit, which is endocytosed following toxin binding to GM1 (S56), covalently modifies the $\alpha$ subunit of $\mathrm{G}_{\mathrm{s}}$, the adenylyl cyclase-stimulating $G$ protein. More specifically, the endocytosed A1 subunit catalyzes covalent bonding of adenosine diphosphoribose from NAD to the $\alpha$ subunit of $G_{s}\left(G_{s} \alpha\right)$, inhibiting the intrinsic GTPase activity of $\mathrm{G}_{\mathrm{s}} \alpha$ thereby preventing self-inactivation of its adenylyl cyclase-stimulating activity $(34,35)$.

$V$. cholerae produces an additional physiologically active peptide, zona occludens toxin, that increases the permeability of tight junctions (S57); however, its relevance to diarrhea is unclear.

Toxigenic E. coli. Toxigenic E. coli, which proliferate in institutional settings and commonly infect American 


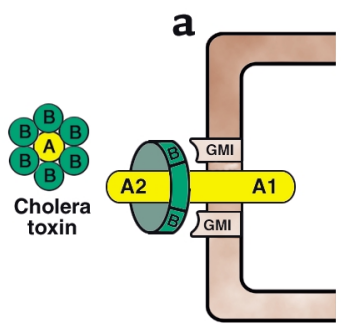

b

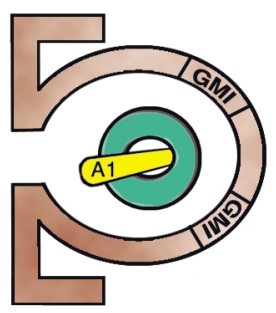

C

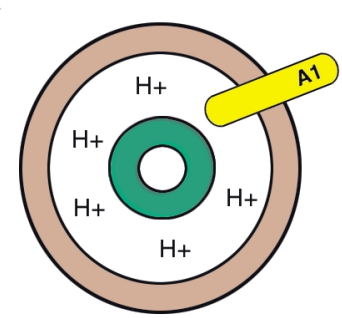

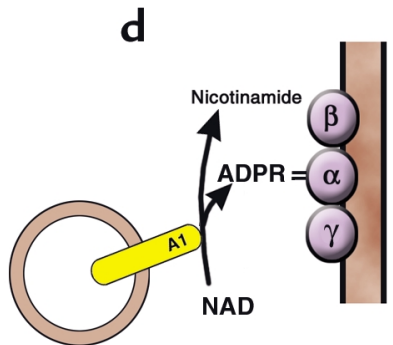

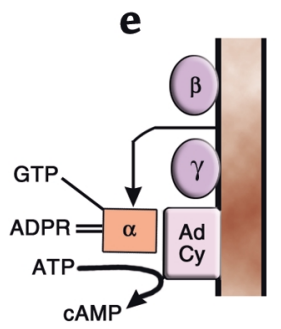

Figure 3

Cellular mechanism of action of cholera toxin. (a) The toxin, through its B subunits, which encircle the enzymically active A subunit, binds to the ubiquitous glycolipid membrane receptor, the monosialoganglioside GM1. (b) The entire complex is endocytosed by both clathrin-dependent and clathrin-independent means. (c) Inwardly directed proton pumps acidify the CT-containing endocytic vesicle, causing the toxin subunits to dissociate. Then the enzymically active A1 peptide is inserted into the vesicle membrane, with its catalytic site exposed to cytoplasm. (d) The A1 peptide is an ADP-ribosyltransferase that cleaves NAD into adenosine diphosphoribose (ADPR) and nicotinamide and covalently bonds the former to the $\alpha$ subunit of the $G_{s}$ adenylyl cyclase-stimulatory $G$ protein. (e) The intrinsic GTPase activity of the ADPR-modified $\alpha$ subunit of $G_{s}$ is markedly inhibited, allowing GTP to remain bound to it; the $\mathrm{G}_{\mathrm{s}} \alpha$-GTP complex separates from its membrane mooring to $\mathrm{G}_{\mathrm{s}} \beta$ and $\mathrm{G}_{\mathrm{s}} \gamma$, attaching to and activating adenylyl cyclase (AdCy).

travelers abroad (traveler's diarrhea), elaborate at least two secretion-stimulating enterotoxins. The first, heatlabile toxin, is a high-molecular weight peptide that is immunologically related to $\mathrm{CT}$ and has the same cellular mechanism of action (S58). The second, heat-stable toxin (STa), is a cysteine-rich, low-molecular weight, heat-stable peptide (S59) that activates guanylate cyclase in the intestinal epithelium (36), thereby activating cGMP-dependent protein kinase (PKG), which, like PKA, can open the CFTR anion channel (37) (Figure 4). Twelve years ago, the brush border receptor for STa was cloned and identified as a guanylyl cyclase, which is activated upon STa binding (38). The existence in mammalian intestine of an enzymatically active receptor for a bacterial enterotoxin raised the question of whether an endogenous ligand for this receptor, one with structural homology to STa, also exists. This question was answered about a year later when a low-molecular weight peptide that mimics STa action and has structural homology to STa was extracted from rat intestinal contents and dubbed "guanylin" (39). This luminally active hormone is, like STa, rich in cysteine (although its four cysteines are two less than in STa). Since it is synthesized in and secreted from goblet cells, and its synthesis is enhanced by oral salt loading, it may play roles in both fluid homeostasis and the moistening of goblet cell mucoid secretions (S60, S61).

As an aside, a close homolog of guanylin, known as uroguanylin, also originates in the gut epithelium and is secreted into the blood by enterochromaffin cells (S62). It is a diuretic (at least in the kidneys of rodents) and may explain why an oral salt load induces a greater diuresis than the same salt load given intravenously. Role of the ENS in enterotoxin-induced secretion. Although the direct effects of CT, heat-labile toxin, and STa on the ion-transporting cells of the intestinal epithelium would seem sufficient to explain the resulting secretion (and in the in vitro mucosal preparation they are sufficient), there is ample evidence from in vivo experiments that the ENS also plays a role - in the mind of some, a dominant role. When segments of mammalian small bowel are perfused with toxin-containing solutions, most of the resulting fluid transport changes can be reversed with neural poisons such as tetrodotoxin and hexamethonium (40). Recent experiments with a specific VIP antagonist demonstrate that much (but not all) of the secretion induced in these enterotoxin perfusions is mediated by VIP (41).

The sequence of events, summarized in Figure 5, seems to be as follows. The enterotoxins attach to endocrine (enterochromaffin) cells on the villus surface of the intestinal epithelium, causing an increase of cAMP or cGMP. cAMP or cGMP triggers these cells to release serotonin, neurotensin, and possibly other peptides into the subepithelial space. These paracrine mediators set in motion a secretory neural reflex that involves (a) afferent enteric neurons that begin subepithelially and end in the myenteric plexus, (b) interneurons that connect the myenteric to the submucosal plexus, and (c) efferent neurons in the submucosal plexus that release VIP (and probably additional secretory stimuli) near the basal surface of the epithelium. The interneuronal effect appears to be mediated by acetylcholine and/or substance P. Finally, the VIP (and 
perhaps another agonist) attaches to receptors on both villus and crypt enterocytes, activating adenylyl cyclase and inducing cAMP-mediated alterations of ion transport (inhibition of absorption in villus cells and stimulation of secretion in crypt cells).

One caveat is that the role of the ENS in enterotoxininduced secretion may be more striking in the animal studies than in the disease itself; in segmental perfusions, enterotoxin does not penetrate into the crypts, whereas, in cholera patients, a direct effect of CT on crypt cells is likely since Vibrio organisms proliferate in the crypts as well as elsewhere in the gut lumen.

\section{Other enteric infections}

Common bacterial causes of enteritis and/or colitis are Shigella, Salmonella, Yersinia, enteroinvasive E. coli, Aeromonas, and Campylobacter. These organisms invade the epithelium and multiply intracellularly, damaging the surface epithelium and causing inflammation. Diarrhea is due both to the epithelial damage (exudation and decreased absorptive capacity) and to the action of inflammatory mediators.

Some viruses also invade the intestinal epithelium, causing enterocyte destruction, inflammation, and a temporary sprue-like syndrome (partial villus atrophy and crypt hypertrophy). These include rotovirus (worldwide, probably the most common cause of diarrhea in infants), certain adenoviruses, and the so-called Norwalk-like agents (S63). These last agents have recently caused a flurry of brief episodes of vomiting and diarrhea among passengers on cruise ships (S64).

Some enteric bacteria produce cytolytic toxins that destroy epithelial cells, interfering with absorption and causing inflammation. These include Shigella dysenteriae (Shiga toxin), a protein synthesis inhibitor; Clostridium difficile, whose A toxin alters cytoskeletal structure, and whose proliferation is induced by broad-spectrum antibiotics; Vibrio parabaemolyticus; Clostridium perfringens; and enteroadherent and enterohemorrhagic E. coli (S65-S68). Most of these bacterial toxins cause breakdown of the cytoskeleton through ADP ribosylation or glucosylation of proteins from the Rho family, which regulate actin polymerization.

Cryptosporidia, a unicellular parasite, caused an epidemic of diarrhea in Milwaukee ten years ago through contamination of the city water supply (S69). Persistent cryptosporidial enteritis can occur in immunocompromised individuals. Cryptosporidia gain entry to the apical cytoplasm of enterocytes by first fusing with the enterocyte microvillus membrane (S70, S71). Heavy infestation with Giardia lamblia leads to disruption of the enterocyte microvillus membrane, which, in turn, leads to malabsorption and diarrhea (S72).

\section{Acute $\mathrm{T}$ cell activation}

Parenteral administration of cytolytic antibodies to $\mathrm{T}$ cell surface antigens causes massive acute, but shortlived, diarrhea, as seen in humans treated for rejection of transplanted organs and, experimentally, in mice (S73). The critical cytokine released in these circumstances appears to be TNF- $\alpha$, presumably because it causes the massive release of prostaglandins and other secretory stimuli.

\section{Pathophysiology of chronic diarrheas}

\section{Congenital diarrheas}

Two rare congenital autosomal-recessive defects in intestinal fluid absorption are associated with diarrhea: congenital chloride diarrhea, which results from a defect in brush border $\mathrm{Cl} / \mathrm{HCO}_{3}$ exchange (see above), and congenital sodium-secretory diarrhea, which results from an as-yet undefined defect in brush border $\mathrm{Na} / \mathrm{H}$ exchange (8, S74). In both cases, nutrient absorption is normal. Also in both, abnormal fluid absorption begins in utero, manifesting itself as maternal polyhydramnios. Congenital chloride diarrhea has been more extensively reported, with clusters of cases found in Finland, Saudi Arabia, Kuwait, and Poland and scattered cases elsewhere (8). In this syndrome, stool $\mathrm{pH}$ is acidic, and metabolic alkalosis develops. Similar acid-base changes are seen in carbohydrate malabsorption and Zollinger-Ellison syndrome. In contrast, in most severe diarrheas, stool $\mathrm{pH}$ is alkaline, and metabolic acidosis develops.

Several other rare congenital defects in nutrient absorption or in intestinal epithelial structure can also cause neonatal diarrhea (S75): congenital sucrase-isomaltase deficiency; congenital glucose-galactose malabsorption; lysinuric protein intolerance, a defect in dibasic amino acid transport across the enterocyte basolateral membrane; acrodermatitis enteropathica, a defect in zinc absorption; and microvillus inclusion

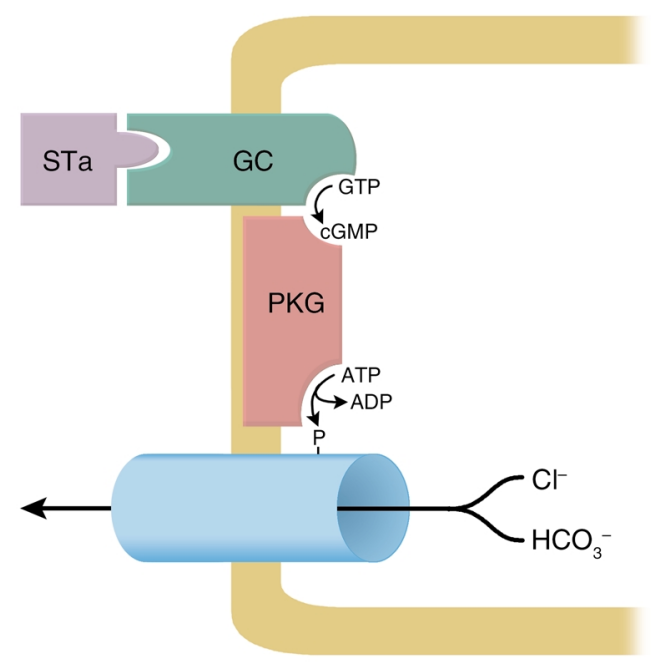

\section{Figure 4}

Cellular mechanism of action of heat-stable E. coli enterotoxin (STa). Luminal toxin binds to and activates guanylyl cyclase C (GC), a brush border enzyme with a high rate of expression in both small intestine and proximal colon. The resulting increase in [cGMP] activates membranebound protein kinase $\mathrm{G}$ (PKG), which, in turn, opens neighboring anion channels or inhibits neighboring $\mathrm{Na} / \mathrm{H}$ and $\mathrm{Cl} / \mathrm{HCO}_{3}$ exchangers (not shown). Guanylin, a mammalian homolog of STa, is the physiologic agonist for the STa-sensitive GC. It is secreted into the lumen by goblet cells. In the duodenum, its action results in an $\mathrm{HCO}_{3}{ }^{-}$-rich secretion. 


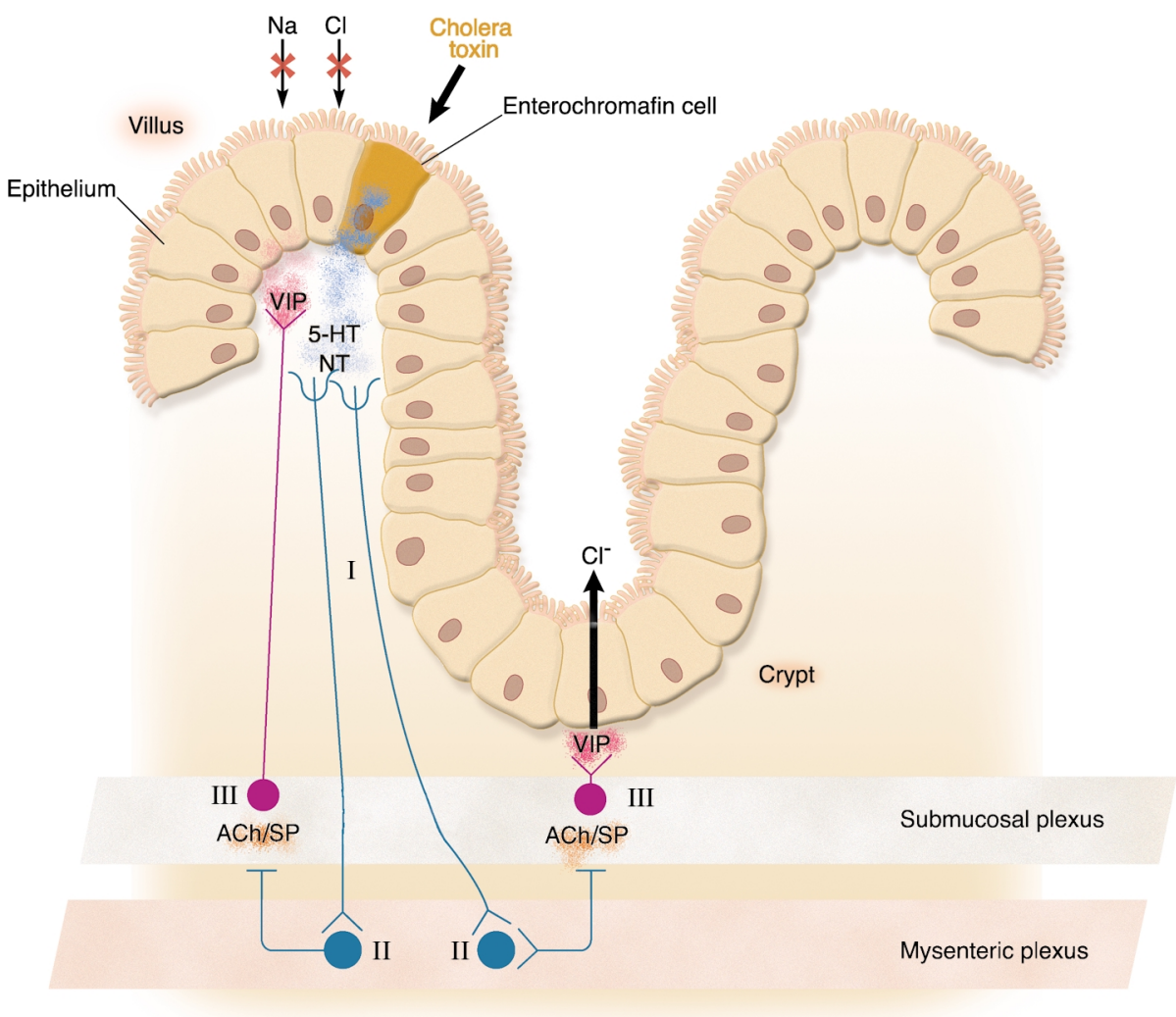

\section{Figure 5}

$C T$ induces secretion, in part, through activation of an intramural neural reflex. Toxin attaches to enterochromaffin cells in the epithelium, causing an increase in [cAMP] there. In response to the latter, serotonin (5-HT), neurotensin (NT), and possibly additional peptides are released. These activate afferent neurons (I), whose axons course from close to the epithelium to the myenteric neural plexus, where they connect with interneurons (II) that, in turn, through release of acetylcholine (ACh) and/or substance $\mathrm{P}(\mathrm{SP})$, activate secreto-motor neurons (III) in the submucosal neural plexus. Axons from these secreto-motor neurons reach the epithelial surface, in both the villus and the crypt regions, releasing VIP and thereby stimulating secretion in crypts and inhibiting nutrient-independent salt absorption in villi. For a comprehensive review, see ref. 42 disease, which includes severe villus atrophy and crypt hypoplasia with the characteristic finding of microvilli contained within vesicles inside the enterocytes.

\section{Hormone-secreting neoplasms}

In several uncommon tumors, hormones are produced and released that directly stimulate intestinal secretion, causing profuse diarrhea or, in one instance (gastrinoma), interfering with nutrient absorption. For a comprehensive review, see ref. 42.

Pancreatic cholera. In patients with pancreatic cholera, certain endocrine neoplasms that occur most commonly in pancreatic islets but occasionally in the proximal intestinal mucosa secrete large quantities of VIP, the enteric secretory neurotransmitter. Some ganglioneuromas (neural crest tumors seen in early childhood) and pheochromocytomas do so also.

Carcinoid syndrome. In carcinoid syndrome patients, cutaneous flushing and profuse diarrhea develop when carcinoid tumors in intestine metastasize to the liver, thereby not only amplifying the tumor mass but also bypassing hepatic detoxification of tumor-released hormones. Very rarely, bronchogenic carcinoids give rise to the syndrome. Carcinoids have been reported to secrete serotonin, bradykinin, substance $\mathrm{P}$, and prostaglandins, all of which are secretory stimuli in the intestine.

Medullary carcinoma of the thyroid. Profuse diarrhea develops in $30 \%$ of patients with medullary carcinoma of the thyroid because of secretion of calcitonin, another secretory stimulus in the intestine.

Zollinger-Ellison syndrome (gastrinoma). In ZollingerEllison syndrome (gastrinoma), both diarrhea and pep- tic ulceration can result from the marked increase in gastric acid production that is associated with gastrinsecreting neoplasms. The diarrhea, unlike those associated with the neoplasms just cited, is at least partly malabsorptive in nature. The marked increase in acid production both presents the intestines with a large volume for reabsorption and lowers $\mathrm{pH}$ in the proximal small bowel, inactivating pancreatic digestive enzymes and precipitating bile acids. Diarrheal stool in these patients has an acidic $\mathrm{pH}$.

Systemic mastocytosis. About half of the patients with the rare neoplasm systemic mastocytosis develop diarrhea, likely due to histamine-induced gastric hypersecretion, a cause similar to that of the diarrhea in Zollinger-Ellison syndrome.

\section{Ileal disease or resection}

Nearly all conjugated bile acids are normally reabsorbed in the distal ileum via $\mathrm{Na}$-bile acid cotransport, with very little reaching the colon (S76-S77). Smallbowel Crohn disease may lead to bile acid malabsorption, since distal ileum is frequently affected; also, obstruction there may develop, necessitating ileal resection. Unabsorbed dihydroxy bile acids such as deoxycholate are amphophiles that, when not incorporated into lipid-containing micelles in the gut lumen, tend to insert into the lipid matrix of the enterocyte or colonocyte brush border membrane. Deconjugation of these bile acids by colonic bacteria enhances their amphophilicity. They activate secretion primarily in the colon but, in the absence of lipids, can also do so in the small bowel. The mechanism for their secretory effect 
is complex, involving both intracellular $\mathrm{Ca}^{2+}$ (probably secondary to membrane phospholipase activation) and cAMP (S78, S79). Bile acid-induced increase in cAMP appears to involve the ENS or mast cells (S80). Diarrhea that results from moderate malabsorption of bile acids can be somewhat reduced by cholestyramine, a resin that binds bile acid anions. But if more than 100 $\mathrm{cm}$ of distal ileum is resected, so much of the enteric bile acid load fails to be reabsorbed that the body's bile acid pool shrinks (43). Then, trapping of additional bile acids with cholestyramine shrinks the bile acid pool further, causing fat malabsorption and thereby worsening the diarrhea. This is because fatty acids that reach the colon undergo bacterial hydroxylation, which renders them amphophilic. Like amphophilic bile acids, and probably by a similar mechanism, they induce secretion (44).

\section{Intestinal lymphectasia}

Obstruction of intestinal lymphatics can be congenital or neoplastic. The resulting increase in interstitial hydrostatic pressure disrupts tight junctions, thereby greatly increasing epithelial permeability not only to water and electrolytes but also to serum proteins. Since chylomicrons are absorbed through lymphatics, fat ingestion by patients with intestinal lymphectasia will increase pressure in their partially obstructed intestinal lymphatics, thereby increasing enteric protein loss and diarrhea. These losses can be lessened by a low-fat diet supplemented with medium-chain triglycerides (which, being water soluble, are absorbed into the portal vein).

Tropical sprue and nontropical sprue (celiac disease, or gluten-sensitive enteropathy)

Sprue histopathology is characterized by total or subtotal villus atrophy, elongation of crypts with increased crypt mitoses, and a dense infiltrate of inflammatory cells, especially plasma cells. The surface epithelium reveals, in addition to flattening, a marked increase in intraepithelial lymphocytes and degenerative changes such as vacuolization and loss of brush border. There are four reasons for the profuse diarrhea that develops in some of these patients: (a) the osmotic force of unabsorbed solutes pulls water and electrolytes into the lumen; (b) villus atrophy and crypt hypertrophy adversely alter the balance between absorptive and secretory cells; (c) unabsorbed bile acids and fatty acids stimulate fluid secretion in the colon; and (d) the inflammatory response generates secretion-stimulating inflammatory mediators. IFN- $\gamma$ and TNF- $\alpha$, whose concentrations in the lamina propria increase in celiac disease, also downregulate nutrient absorption (S73, S81-S83).

\section{Diabetes mellitus}

Diarrhea accompanied by rectal incontinence is an occasional complication of long-standing, insulindependent diabetes. It typically occurs in patients with poor diabetic control and peripheral neuropathy. Intestinal biopsies in such patients are usually normal, and nutrient malabsorption or bacterial overgrowth is present only in a minority of cases. In most instances, the diarrhea is secondary to degeneration of adrenergic nerves that, as mentioned above, are antisecretory and/or proabsorptive in intestinal fluid homeostasis $(45$, S84). Other evidence of autonomic neuropathy can usually be elicited. There is anecdotal evidence that diabetic diarrhea can sometimes be controlled with an $\alpha_{2}$ agonist such as clonidine or with a somatostatin ana$\log$ such as octreotide (S85, S86).

\section{Bacterial overgrowth}

Normally, only a relatively small number of bacteria proliferate in the small bowel. In the presence of local stasis or recirculation of luminal contents, however, bacteria will proliferate in the affected segment of small bowel (e.g., afferent loop dysfunction after gastrojejunostomy; jejunal diverticula; strictures or enterocolic fistulas in Crohn disease; and ineffective peristalsis in scleroderma or diabetes). If the stasis occurs proximally, the bacteria will deconjugate and partially dehydroxylate bile acids, leading to their rapid diffusional reabsorption. The resulting decrease in concentration of effective bile salts can cause fat malabsorption. As mentioned above, lipids that are hydroxylated by bacteria are thereby converted into secretion-stimulating amphophiles. In addition, bacterial proteases can inactivate brush border oligosaccharidases, leading to carbohydrate malabsorption.

\section{Inflammatory bowel disease}

In regional enteritis (Crohn disease), damage to or resection of the distal ileum can lead to bile acid malabsorption, which, as outlined above, causes diarrhea. Also in Crohn disease, enterocolic fistulas may develop, resulting in bacterial overgrowth of the small bowel, and this, as outlined just above, causes diarrhea. In both ulcerative colitis and Crohn colitis, inflammatory mediators such as prostaglandins stimulate colonic secretion, contributing to diarrhea. Cytokines generated in the inflamed mucosa may also downregulate fluid-absorptive mechanisms (S73, S81-S83).

\section{Principles of management}

\section{Oral rehydration therapy}

Cholera and E. coli enterotoxins stimulate fluid secretion without injuring the intestinal epithelium; in particular, they do not impair the cellular processes for nutrient absorption. Even in viral enteritis, which does cause epithelial injury, considerable absorptive capacity remains. Long ago it was noted that, in cholera, diarrheal losses could not be replaced by oral administration of a simple salt solution - it only added to diarrheal volume. We now know why: the cAMP response to $\mathrm{CT}$ inhibits nutrient-independent salt absorption (i.e., $\mathrm{Na} / \mathrm{H}$ and $\mathrm{Cl} / \mathrm{HCO}_{3}$ exchanges). In the 1960s, investigators in Dacca and Calcutta, mindful of the newly emerging concept of $\mathrm{Na}$-coupled absorption of sugars and amino acids, found that, when they added glucose to an orally administered salt solution (an isosmotic solution with approximately equimolar amounts of $\mathrm{Na}^{+}$and glucose), cholera patients were 
able to absorb the solution $(46,47)$. In areas where the incidence of severe diarrhea is high and health workers and sterile intravenous solutions are scarce, the use of an oral rehydration solution administered by family members has saved many lives.

Although such solutions can replace diarrheal losses, they do not facilitate reabsorption of secreted fluid and therefore do not lessen diarrhea. Some reabsorption of secreted fluid can be achieved by substitution of glucose polymers for free glucose in the oral rehydration solution. Normally, the rate of hydrolysis of starch to maltose is slow compared with the rates of hydrolysis of maltose and of absorption of free glucose. Thus, as fast as glucose becomes available, it is absorbed, and hyperosmolarity of the luminal contents never develops. A glucose polymer can be thought of as a "glucose battery," providing a continuous supply of glucose for absorption under isosmotic conditions. Solutions containing extracts from rice or other grains are increasingly being used for oral rehydration and appear not only to replace fluid losses but also to lessen diarrhea (S87).

The same principle may apply to proteins and to the amino acids and oligopeptides generated from them, but there is relatively little experimental evidence of their efficacy.

\section{Pharmacologic intervention}

Antibiotics. To minimize development of drug-resistant organisms, antibiotics should not be used for relatively mild, self-limited infectious diarrheas. When the diarrhea is hemorrhagic, seriously dehydrating, associated with serious systemic signs and symptoms, or of longer than 5 days' duration without improvement, antibiotic use is appropriate. Fluoroquinolones are commonly used. C. difficile-induced diarrhea should be treated by withdrawal of the offending antibiotic and oral administration of either metronidazole or vancomycin.

Antidiarrbeals. In mild diarrheas, antimotility agents (e.g., loperamide) will lessen stool frequency and, by increasing the time of contact with the gut epithelium, will also lessen stool volume. Such agents are contraindicated in severe diarrhea, because they may cause pooling of large fluid volumes in paralyzed bowel loops.

Since intestinal ion transport mechanisms operate within a complex regulatory framework, drugs that either mimic or potentiate the effects of antisecretory/proabsorptive hormones or neurotransmitters are proving useful. Recently, an enkephalinase inhibitor, racecedotril (also known as acetorphan), has been shown to lessen the volume of acute infectious diarrhea in children, presumably by preventing breakdown of enkephalins in the mucosa, which are anti-secretory (S88, S89). Its action is confined to intestine and, unlike loperamide, it doesn't reduce transit time.

Somatostatin analogues (e.g., octreotide) will sometimes control diarrhea. In hormone-secreting neoplasms, they block hormone production by the tumor (42). Since they also appear to have a direct antisecretory effect on the gut epithelium (S90), they have been employed for treating cancer chemotherapy-induced diarrhea. Anecdotal experience with an $\alpha_{2}$ agonist, clonidine, suggests its utility in some diarrheas, especially in diabetic diarrhea, but severe side effects limit its usefulness; one side effect, postural hypotension, would be problematic in dehydrated individuals.

Thus far, drugs that block the actions of secretagogues, such as prostaglandin synthase inhibitors, have not proven effective as antidiarrheals perhaps because of the multiplicity of locally produced secretagogues.

Two cellular sites provide targets for the development of transport inhibitors: the apical anion channel (CFTR) and the basolateral cAMP-sensitive $\mathrm{K}^{+}$channel. In the laboratory, specific blockers for each have been identified. Of particular interest, a class of high potency inhibitors of the CFTR anion channel (thiazolidinones) has recently been identified through screening a large number of compounds in transfected cells (48). One of these, on a single intraperitoneal injection into mice $(250 \mu \mathrm{g} / \mathrm{kg})$, reduced CT-induced secretion by more than $90 \%$.

\section{Overview of treatment}

Understandably, therapies for epidemic infectious diarrheas must differ somewhat from those for chronic diarrheas. Epidemic cholera is most effectively dealt with at the contamination level. Cholera vaccines were not covered in this review; they are only partially effective and then only temporarily. An effective oral vaccine is not available. Efforts to improve sanitation are of more practical value. In a recent study, simple filtration of drinking water through cloth, such as a flat fragment of an old sari, reduced cholera incidence in Bengladeshi villages by $50 \%$ (49). Once infection has occurred, ORS remains the mainstay of treatment.

Several drugs that either have proven or may prove useful in treating chronic and some acute diarrheas were cited above. In addition, diarrheas with an inflammatory component can be treated with anti-inflammatory agents, most notably glucocorticoids.

Note: Due to space constraints, a number of important references could not be included in this reference list. Interested readers can find a supplementary reference list at (http://www.jci.org/cgi/content/full/111/7/931/DC1).

1. Schultz, S.G., Fuisz, R.E., and Curran, P.F. 1966. Amino acid and sugar transport in rabbit ileum. J. Gen. Physiol. 49:849-866.

2. Ganapathy, V., and Leibach, F.H. 1985. Is intestinal peptide transport energized by a proton gradient? Am. J. Physiol. 249:G153-G160.

3. Turnberg, L.A., Fordtran, J.S., Carter, N.W., and Rector, F.C., Jr. 1970. Mechanism of bicarbonate absorption and its relationship to sodium transport in the human jejunum. J. Clin. Invest. 49:548-556.

4. Turnberg, L.A., Bieberdorf, F.A., Morawski, S.G., and Fordtran, J.S. 1970. Interrelationships of chloride, bicarbonate, sodium, and hydrogen transport in the human ileum. J. Clin. Invest. 49:557-567.

5. Hoogerwerf, W.A., et al. 1996. NHE2 and NHE3 are human and rabbit intestinal brush-border proteins. Am. J. Physiol. 270:G29-G41.

6. Schultheis, P.J., et al. 1998. Renal and intestinal absorptive defects in mice lacking the NHE3 Na+/H+ exchanger. Nat. Genet. 19:282-285.

7. Melvin, J.E., Park, K., Richardson, L., Schultheis, P.J., and Shull, G.E. 1999. Mouse down-regulated in adenoma (DRA) is an intestinal Cl/HCO3- exchanger and is up-regulated in colon of mice lacking the NHE3 Na+/H+ exchanger. J. Biol. Chem. 274:22855-22861.

8. Kere, J., Lohi, H., and Hoglund, P. 1999. Genetic disorders of membrane transport. III. Congenital chloride diarrhea. Am. J. Physiol. 276:G7-G13.

9. De, S.N. 1959. Enterotoxicity of bacteria-free culture-filtrate of Vibrio cholerae. Nature. 183:1533-1534.

10. Dutta, N.K., Panse, M.W., and Kulkarni, D.R. 1959. Role of cholera toxin in experimental cholera. J. Bacteriol. 78:594-595. 
11. Gangarosa, E.J., Beisel, W.R., Benyajatic, C., Sprinz, H., and Piyaratn, P. 1960. The nature of the gastrointestinal lesion in Asiatic cholera and its relation to pathogenesis: a biopsy study. American Journal of Tropical Med icine and Hygeine. 9:125-135.

12. Field, M. 1971. Ion transport in rabbit ileal mucosa. II. Effects of cyclic 3', 5'-AMP. Am. J. Physiol. 221:992-997.

13. Kimberg, D.V., Field, M., Johnson, J., Henderson, A., and Gershon, E. 1971. Stimulation of intestinal mucosal adenyl cyclase by cholera enterotoxin and prostaglandins. J. Clin. Invest. 50:1218-1230.

14. Field, M., Fromm, D., Al-Awqati, Q., and Greenough, W.B., 3rd. 1972 Effect of cholera enterotoxin on ion transport across isolated ileal mucosa. J. Clin. Invest. 51:796-804.

15. Tabcharani, J.A., Chang, X.B., Riordan, J.R., and Hanrahan, J.W. 1991. Phosphorylation-regulated $\mathrm{Cl}$ - channel in $\mathrm{CHO}$ cells stably expressing the cystic fibrosis gene. Nature. 352:628-631.

16. Kunzelmann, K., et al. 2001. Cloning and function of the rat colonic epithelial K+ channel KVLQT1. J. Membr. Biol. 179:155-164.

17. Payne, J.A., et al. 1995. Primary structure, functional expression, and chromosomal localization of the bumetanide-sensitive $\mathrm{Na}-\mathrm{K}-\mathrm{Cl}$ cotransporter in human colon. J. Biol. Chem. 270:17977-17985.

18. Sheppard, D.N., and Welsh, M.J. 1999. Structure and function of the CFTR chloride channel. Physiol. Rev. 79(Suppl. 1):S23-S45.

19. O'Loughlin, E.V., et al. 1991. Abnormal epithelial transport in cystic fibrosis jejunum. Am. J. Physiol. 260:G758-G756.

20. Grubb, B.R. 1997. Ion transport across the murine intestine in the absence and presence of CFTR. Comp. Biochem. Physiol. A Physiol. 118:277-282.

21. Neilson, M.S., Warth, R., Bleich, M., Weyland, B., and Greger, R. 1998 The basolateral $\mathrm{Ca} 2+$-dependent $\mathrm{K}+$ channel in rat colonic crypt cells. Pflugers Arch. 435:267-272.

22. Chang, E.B., Field, M., and Miller, R.J. 1982. Alpha-2-adrenergic receptor regulation of ion transport in rabbit ileum. Am. J. Physiol. 242:G237-G242.

23. Madara, J.L. 1987. Intestinal absorptive cell tight junctions are linked to cytoskeleton. Am. J. Physiol. 253:C171-C175.

24. Fordtran, J.S., Rector, F.C., Jr., Ewton, M.F., Soter, N., and Kinney, J. 1965 Permeability characteristics of the human small intestine. J. Clin. Invest. 44:1935-1944.

25. Poulsen, J.H., Fischer, H., Illek, B., and Machen, T.E. 1994. Bicarbonate conductance and $\mathrm{pH}$ regulatory capability of cystic fibrosis transmembrane conductance regulator. Proc. Natl. Acad. Sci. U. S. A. 91:5340-5344

26. Binder, H.J., Sangan, P., and Rajendran, V.M. 1999. Physiological and molecular studies of colonic H+,K+-ATPase. Semin. Nephrol. 19:405-414.

27. Roggin, G.M., Banwell, J.G., Yardley, J.H., and Hendrix, T.R. 1972. Unimpaired response of rabbit jejunum to cholera toxin after selective damage to villus epithelium. Gastroenterology. 63:981-988.

28. Crawford, I., et al. 1991. Immunocytochemical localization of the cystic fibrosis gene product CFTR. Proc. Natl. Acad. Sci. U. S. A. 88:9262-8266.

29. Trezise, A.E.O., and Buchwald, M. 1991. In vivo cell-specific expression of the cystic fibrosis transmembrane conductance regulator. Nature. 353:434-437.

30. Ameen, N.A., Ardito, T., Kashgarian, M., and Marino, C.R. 1995. A unique subset of rat and human intestinal villus cells express the cyctic fibrosis transmembrane conductance regulator. Gastroenterology.
108:1016-1023

31. Singh, S.K., Binder, H.J., Boron, W.F., and Geibel, J.P. 1995. Fluid absorption in isolated perfused colonic crypts. J. Clin. Invest. 96:2373-2379.

32. Knickelbein, R.G., Aronson, P.S., and Dobbins, J.W. 1988. Membrane distribution of sodium-hydrogen and chloride-bicarbonate exchangers in crypt and villus cell membranes from rabbit ileum. J. Clin. Invest. 82:2158-2163.

33. King, C.A., and van Heyningen, W.E. 1973. Deactivation of cholera toxin by a sialidase-resistant monosialosyl ganglioside. J. Infect. Dis. 127:639-647.

34. Gill, D.M., and King, C.A. 1975. The mechanism of action of cholera toxin in pigeon erythrocyte lysates. J. Biol. Chem. 250:6424-6432.

35. Cassel, D., and Selinger, Z. 1977. Mechanism of cholera toxin activation of adenylate cyclase: inhibition of GTP hydrolysis at the regulatory site. Proc. Natl. Acad. Sci. U. S. A. 74:3307-3311.

36. Field, M., Graf, L.H., Jr., Laird, W.J., and Smith, P.L. 1978. Heat-stable enterotoxin of Escherichia coli: in vitro effects on guanylate cyclase activity, cyclic GMP concentration and ion transport in small intestine. Proc. Natl. Acad. Sci. U. S. A. 75:2800-2804.

37. Vaandrager, A.B., et al. 1998. Membrane targeting of cGMP-dependent protein kinase is required for cystic fibrosis transmembrane conductance regulator $\mathrm{Cl}$ - channel activation. Proc. Natl. Acad. Sci. U. S. A. 95:1466-1471.

38. Schulz, S., Green, C.K., Yuen, P.S., and Garbers, D.L. 1990. Guanylyl cyclase is a heat-stable enterotoxin receptor. Cell. 63:941-948.

39. Currie, M.G., et al. 1992. Guanylin: an endogenous activator of intestinal guanylate cyclase. Proc. Natl. Acad. Sci. U. S. A. 89:947-951.

40. Lundgren, O. 2002. Enteric nerves and diarrhea. Pharmacol. Toxicol. 90:109-120.

41. Mourad, F.H., and Nassar, C.F. 2000. Effect of vasoactive intestinal polypeptide (VIP) antagonism on rat jejunal fluid and electrolyte secretion induced by cholera and Escherichia coli enterotoxins. Gut. 47:382-386.

42. Jensen, R.T. 1999. Overview of chronic diarrhea caused by functional neuroendocrine neoplasms. Semin. Gastrointest. Dis. 10:156-172.

43. Hofmann, A.F., and Poley, J.R. 1972. Role of bile acid malabsorption in pathogenesis of diarrhea and steatorrhea in patients with ileal resection. I. Response to cholestyramine or replacement of dietary long chain triglyceride by medium chain triglyceride. Gastroenterology. 62:918-934.

44. Racusen, L.C., and Binder, H.J. 1979. Ricinoleic acid stimulation of active anion secretion in colonic mucosa of the rat. J. Clin. Invest. 63:743-749.

45. Chang, E.B., Bergenstal, R.M., and Field, M. 1985. Diarrhea in streptozocin-treated rats. Loss of adrenergic regulation of intestinal fluid and electrolyte transport. J. Clin. Invest. 75:1666-1670.

46. Pierce, N.F., et al. 1968. Effect of intra-gastric glucose-electrolyte infusion upon water and electrolyte balance in Asiatic cholera. Gastroenterology. 55:333-343.

47. Hirschhorn, N. 1968. Decrease in net stool output in cholera during intestinal perfusion with glucose-containing solution. N. Engl. J. Med. 279:176-188

48. Ma, T., et al. 2002. Thiazolidinone CFTR inhibitor identified by highthroughput screening blocks cholera toxin-induced intestinal fluid secretion. J. Clin. Invest. 110:1651-1658.

49. Colwell, R.R., et al. 2003. Reduction of cholera in Bengladeshi villages by simple filtration. Proc. Natl. Acad. Sci. U. S. A. 100:1051-1055. 